\title{
Psychotherapy for subclinical depression: meta-analysis
}

Pim Cuijpers, Sander L. Koole, Annemiek van Dijke, Miquel Roca, Juan Li

and Charles F. Reynolds III

\section{Background}

There is controversy about whether psychotherapies are effective in the treatment of subclinical depression, defined by clinically relevant depressive symptoms in the absence of a major depressive disorder.

\section{Aims}

To examine whether psychotherapies are effective in reducing depressive symptoms, reduce the risk of developing major depressive disorder and have comparable effects to psychological treatment of major depression.

\section{Method}

We conducted a meta-analysis of 18 studies comparing a psychological treatment of subclinical depression with a control group.

\section{Results}

The target groups, therapies and characteristics of the included studies differed considerably from each other, and the quality of many studies was not optimal. Psychotherapies did have a small to moderate effect on depressive symptoms against care as usual at the post-test assessment $(g=0.35$, 95\% Cl 0.23-0.47; NNT =5, 95\% Cl 4-8) and significantly reduced the incidence of major depressive episodes at 6 months $(R R=0.61)$ and possibly at 12 months $(R R=0.74)$. The effects were significantly smaller than those of psychotherapy for major depressive disorder and could be accounted for by non-specific effects of treatment.

\section{Conclusions}

Psychotherapy may be effective in the treatment of subclinical depression and reduce the incidence of major depression, but more high-quality research is needed.

\section{Declaration of interest}

None.
Subclinical depression is highly prevalent, ${ }^{1,2}$ is associated with decreased levels of health-related quality of life, ${ }^{3,4}$ increased use of health services, ${ }^{5}$ economic costs, ${ }^{6}$ and mortality rates. ${ }^{7}$ Individuals are considered to have subclinical depression when they display clinically relevant depressive symptoms but standard diagnostic criteria for a depressive disorder are not met. It can be defined according to the DSM (at least one of the core symptoms for depression is met as well as one other symptom, but no more than four symptoms in total), or as a score above a cut-off level on a self-report depression scale while the criteria for a depressive disorder according to a diagnostic interview are not met. Subclinical depression is important from a clinical perspective not only because it can be a disabling condition that needs treatment, but also because of the associated risk of developing major depression, which may be averted by treatment.

A recent meta-analysis showed that it is unlikely that antidepressants and benzodiazepines have a clinically important advantage over placebo in individuals with subclinical depression. ${ }^{8}$ It is not clear, however, whether psychological treatments are effective in subclinical depression. In an earlier review we identified only seven randomised trials examining the effects of psychological treatments of subclinical depression. ${ }^{9}$ These studies did confirm that psychological treatments have moderate effects on subclinical depression, but the confidence intervals around these effects were broad, and it could not be established that these treatments were able to reduce the incidence of major depressive disorder at follow-up. Since then, the number of randomised trials has increased considerably (as of January 2013, we identified 18 trials). We decided therefore to conduct a new meta-analysis to examine whether we could confirm the earlier finding that psychotherapy is effective in subclinical depression, and whether psychotherapeutic interventions reduce the incidence of major depressive episodes.

\section{Method}

We constructed a database of papers on the psychological treatment of depression that has been described in detail elsewhere, ${ }^{10}$ and has been used in a series of earlier published meta-analyses (www.evidencebasedpsychotherapies.org). This database has been continuously updated through comprehensive literature searches (from 1966 to January 2013). In these searches we examined 14164 abstracts from PubMed (3638 abstracts), PsycINFO (2824), EMBASE (4682) and the Cochrane Central Register of Controlled Trials (3020). These abstracts were identified by combining terms indicative of psychological treatment and depression (both MeSH terms and text words). For this database we also checked the primary studies from 42 meta-analyses of psychological treatment for depression to ensure that no published study was missed. From the 14164 abstracts (10 474 after removal of duplicates) we retrieved 1476 full-text papers for possible inclusion in the database. We included randomised, controlled trials in which a psychological intervention was compared with a control condition in participants with clinically relevant depressive symptoms but no major depressive disorder or dysthymia, as established with help of a standardised diagnostic interview such as the Structured Clinical Interview for DSM Disorders (SCID), Composite International Diagnostic Interview (CIDI) or the Schedules for Clinical Assessment in Neuropsychiatry (SCAN) to exclude the presence of a full-blown mood disorder at baseline. Clinically relevant depressive symptoms were defined as scoring above a cut-off level on a self-rating depression questionnaire; scoring above a cut-off level on a clinician-rated instrument; or meeting criteria for minor depression according to the DSM, ICD or Research Diagnostic Criteria. We also included studies in which participants with a 
diagnosed depressive disorder were examined, but only when results were specifically reported for participants with subclinical depression. Studies examining stepped-care models for the treatment of depression were also included, as these usually have a strong focus on psychological treatments. We excluded studies in adolescents or children ( $\leqslant 18$ years). Comorbid general medical or psychiatric disorders were not used as an exclusion criterion. No language restriction was applied.

To compare the effects of psychotherapy for subclinical depression with those of psychotherapy for major depressive disorder, we also selected studies in which participants met criteria for major depression at baseline. We used the same inclusion criteria as for the studies on subclinical depression, except that patients had to meet criteria for major depression according to a diagnostic interview. Studies among patients with other depressive disorders (dysthymia, adjustment disorders) were excluded, as were studies of people receiving in-patient treatment.

\section{Quality assessment and data extraction}

We assessed the validity of included studies using five of the six criteria of the 'risk of bias' assessment tool developed by the Cochrane Collaboration. ${ }^{11}$ This tool assesses possible sources of bias in randomised trials, including the adequate generation of allocation sequence, concealment of allocation to conditions, prevention of knowledge of the allocated intervention (masking of assessors), dealing with incomplete outcome data (this was assessed as positive when intention-to-treat analyses were conducted, meaning that all randomised patients were included in the analyses) and selective outcome reporting. The sixth item of the risk of bias assessment tool (other problems that could put it at a high risk of bias) was not used in this study because we found no clear indication in any of the studies that this had influenced the validity of the study. We also coded additional aspects of the included studies such as participant characteristics (recruitment method: community, from clinical samples or other; target group: adults in general or more specific target groups such as older adults); intervention characteristics (format: individual, group or guided self-help; number of sessions; type of psychotherapy: cognitive-behavioural therapy or other); and study characteristics (type of control group: care as usual, in which no specific intervention was offered to participants although they could use any care or treatment they wanted, or other control group). Quality assessment and data extraction were done by two independent researchers.

\section{Statistical analysis}

For each comparison between a psychotherapy condition and a control group, the effect size indicating the difference between the two groups at the post-test assessment was calculated (Hedges' $g$ ). Effect sizes were calculated by subtracting (post-test) the average score of the psychotherapy group from the average score of the control group, and dividing the result by the pooled standard deviation. Because several studies had small samples we corrected the effect size for small sample bias according to the procedures suggested by Hedges \& Olkin. ${ }^{12}$ In the calculation of effect sizes we used only instruments that explicitly measured symptoms of depression, such as the Beck Depression Inventory (BDI) or the Hamilton Rating Scale for Depression (HRSD). ${ }^{13,14}$ If more than one depression measure was used the mean of the effect sizes was calculated, so that each comparison yielded only one effect (using the methods described by Borenstein et al). ${ }^{15}$ If dichotomous outcomes were reported without means and standard deviations we used the procedures described by Borenstein et al to calculate the standardised mean difference. ${ }^{15}$
To calculate pooled mean effect sizes, we used the computer program Comprehensive Meta-Analysis version 2.2.021 for Windows. Because we expected considerable heterogeneity among the studies, we employed a random effects pooling model. Because the standardised mean difference (Hedges' $g$ ) is not easy to interpret from a clinical perspective we transformed these values into the number needed to treat (NNT), using the formulas provided by Kraemer \& Kupfer. ${ }^{16}$ The NNT indicates the number of patients that have to be treated in order to generate one additional positive outcome. ${ }^{17}$

As a test of homogeneity of effect sizes we calculated the $I^{2}$ statistic as an indicator of heterogeneity ( $0 \%$ no observed heterogeneity, 25\% low, 50\% moderate and 75\% high heterogeneity). We calculated $95 \%$ confidence intervals around $I^{2}$, using the non-central chi-squared approach within the 'heterogi' module for Stata. ${ }^{18,19}$ We also calculated the $Q$ statistic, but only report whether this was significant. Subgroup analyses were conducted according to the mixed effects model, ${ }^{15}$ in which studies within subgroups were pooled with the random effects model, whereas tests for significant differences between subgroups were conducted with the fixed effects model. For continuous variables we used meta-regression analyses to test whether there was a significant relationship between the continuous variable and effect size, as indicated by a $Z$ value and an associated $P$ value. Multivariate meta-regression analyses in which more than one predictor was entered simultaneously were conducted in Stata/MP version 11.0 for Mac, because these analyses cannot be conducted in Comprehensive Meta-analysis. In order to avoid collinearity, we first calculated the correlation between predictors but found no correlation higher than $r=0.60$. Publication bias was tested by inspecting the funnel plot on primary outcome measures and by Duval \& Tweedie's trim and fill procedure, ${ }^{20}$ which yields an estimate of the effect size after the publication bias has been taken into account (as implemented in Comprehensive Meta-analysis version 2.2.021). We also conducted Egger's test of the intercept to quantify the bias captured by the funnel plot and test whether it was significant.

\section{Results}

Eighteen studies met the inclusion criteria for the meta-analysis of psychotherapy for subclinical depression (Fig. 1). ${ }^{21-38}$ Another 56 studies compared the effects of psychotherapy with a control group in patients with a diagnosed major depressive disorder. These 56 studies were included for the comparisons between psychotherapy for subclinical depression and major depression. Selected characteristics and references for the 56 studies examining psychotherapy for major depressive disorder are presented in online Appendix DS1.

\section{Characteristics of included studies}

The 18 studies on subclinical depression included 1913 participants: 947 in the treatment groups and 966 in the control groups. Selected characteristics of the included studies appear in online Table DS1. There were considerable differences between the studies in terms of recruitment setting, target group and definition of subclinical depression (scoring above a cut-off point on a self-report instrument $v$. DSM criteria for minor depression). Different types of therapy were used, although most interventions were based on cognitive-behavioural therapy (CBT), and the interventions also differed in terms of treatment format (individual, group, telephone-based, guided self-help) and number of treatment sessions (range 6-16). The quality of the included studies varied (Table DS1). Seven of the 18 studies 


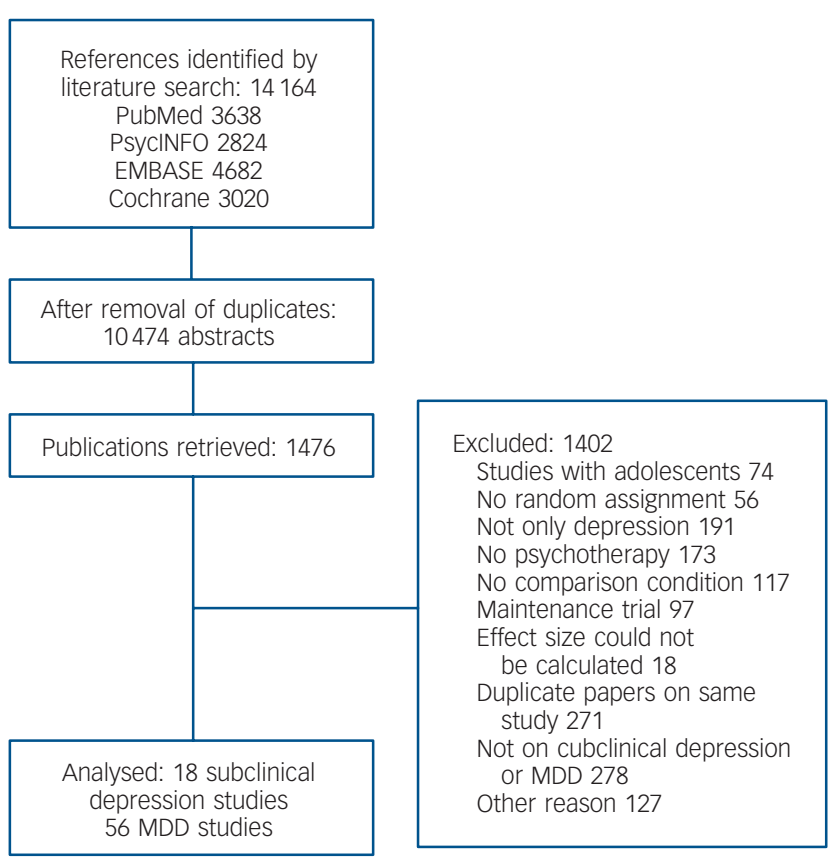

Fig. 1 Flowchart of inclusion of studies (MDD, major depressive disorder)

reported an adequate sequence generation. Eight studies reported allocation to conditions by an independent (third) party. Three of the four studies in which a clinician-rated outcome was used reported masking of outcome assessors (the other 14 studies used only self-report measures) and in 13 studies intention-to-treat analyses were conducted. In five studies, the risk of selective outcome reporting was assessed as low. Five studies met all five quality criteria, 6 met two to four criteria and the remaining 7 studies had a lower quality (none or one of the four criteria).

\section{Short-term effects on depressive symptoms}

The effects of psychotherapy compared with the control conditions at post-test assessment were available for 14 studies. The pooled effect size was $g=0.35$ (95\% CI $0.23-0.47)$, which corresponds with an NNT of 5.10 (95\% CI 3.85-7.69). Heterogeneity was low $\left(I^{2}=13,95 \%\right.$ CI $\left.0-51\right)$. The results of these analyses are presented in Table 1. Figure 2 gives a forest plot of the effect sizes and their confidence intervals. The results limited to the Center for Epidemiological Studies - Depression scale (CES-D) and the BDI-II were comparable to the overall analyses, as were the results for the self-report instruments. The four studies in which a clinician-rated instrument was used, however, resulted in a non-significant effect size of $-0.04(95 \%$ CI -0.33 to 0.25 ). We found few indications of publication bias. Visual inspection of the funnel plot suggested symmetry, and Duval \& Tweedie's trim and fill procedure indicated that no study was missing (the imputed effect size was exactly the same as the actual effect size). Egger's test was also not significant $(P>0.1)$. The subgroup analyses did not results in any significant difference between subgroups, except for the difference between outcomes based on self-report measures and outcomes based on an interview by a (masked) assessor.

\section{Long-term effects on incidence of major depression}

We calculated the relative risk (RR) of developing a major depressive disorder in the treatment and control groups at follow-up, as well as the NNT (defined as the inverse of the risk difference). Results are presented in Table 2 and Fig. 3. Treatment significantly reduced the incidence of major depressive episodes at 6-month follow-up $(\mathrm{RR}=0.61,95 \%$ CI $0.37-0.99 ; \quad P<0.05$; $I^{2}=19,95 \%$ CI $0-83$; that is, a reduction in incidence of $39 \%)$, and possibly at 12 -month follow-up $(\mathrm{RR}=0.74,95 \% \mathrm{CI}$ $0.50-1.10$; a reduction in incidence of $26 \%$ ). Change in the numbers needed to treat was also significant at 6-month follow-up $(\mathrm{NNT}=10.3,95 \%$ CI 6.3-28.6) and at 12-month follow-up $(\mathrm{NNT}=16.4,95 \%$ CI $8.5-250)$.

\section{Comparison with psychotherapy for major depression}

The unadjusted effect size for psychotherapy for major depression $(g=0.63,95 \%$ CI $0.54-0.73)$ was significantly larger than that for psychotherapy for subclinical depression $(g=0.35, P<0.01)$. In the multivariate analyses, in which we adjusted for study quality and other characteristics of the studies, this difference between subclinical depression and major depression remained significant (Table 3). In a (manual) back-step meta-regression analysis, in which we dropped the least significant variable in each step until only significant predictors were retained in the model (parsimonious model in Table 3), the difference between subclinical and major depression was still significantly associated with the effect size $(P<0.01)$.

\section{Discussion}

We found that psychological treatments had a small to moderate but statistically significant effect on subclinical depression, with an NNT of about 5. We also found that these treatments had a significant preventive effect on the onset of major depressive disorder at 6 months $(\mathrm{RR}=0.61, \mathrm{NNT}=10)$ and possibly at 12 months $(\mathrm{RR}=0.74, \mathrm{NNT}=16)$. However, the included studies differed considerably from each other in terms of target groups, treatment, and design and type of control group, and the quality of most studies in this field was found to be suboptimal. Furthermore the clinician-rated outcomes did not indicate a significant result of these treatments; positive results were based only on self-report measures. These results should therefore be considered with caution and verified in further research. Because most studies used a waiting list or care as usual control group, it is not surprising that small effects were found. These might be due to placebo or non-specific effects of the treatments. Most studies of pharmacotherapy for subclinical depression have used a pillplacebo control group, ${ }^{8}$ and it is likely that if these were compared with waiting lists or care as usual they would result in effects similar to the psychotherapies. This suggests that the effects of the psychological interventions may in part be explained by non-specific or placebo effects. The comparability of psychotherapy and pharmacotherapy studies of subclinical depression is limited by these methodological differences. The effects of psychological treatments on subclinical depression are not as large as those on major depression, even after adjusting for the characteristics of the populations, therapies, study quality and other characteristics of the studies. This is not surprising, as possibilities for improvement are more limited in subclinical depression than in major depression.

\section{Limitations}

This meta-analysis has several important limitations. First, we have already noted the considerable differences between the target groups, interventions and characteristics of the included studies, and the low quality of several of the included studies. We did find 


\begin{tabular}{|c|c|c|c|c|c|c|c|c|}
\hline & Studies & $g^{a}$ & $95 \% \mathrm{Cl}$ & $I^{2}$ & $95 \% \mathrm{Cl}$ & $P^{\mathrm{b}}$ & NNT & $95 \% \mathrm{Cl}$ \\
\hline All studies & 14 & 0.35 & 0.23 to 0.47 & 13 & 0 to 51 & & 5.1 & 3.85 to 7.69 \\
\hline CES-D only & 5 & 0.42 & 0.23 to 0.61 & 0 & 0 to 79 & & 4.3 & 2.99 to 7.69 \\
\hline BDI-II only & 3 & 0.38 & 0.14 to 0.63 & 46 & 0 to 84 & & 4.7 & 2.91 to 12.82 \\
\hline \multicolumn{9}{|l|}{ Type of outcome } \\
\hline Self-rated & 11 & 0.42 & 0.30 to 0.53 & 0 & 0 to 60 & & 4.3 & \multirow[t]{2}{*}{3.42 to 5.95} \\
\hline Clinician-rated & 4 & -0.04 & -0.33 to 0.25 & 0 & 0 to 85 & & $\mathrm{NR}^{\mathrm{C}}$ & \\
\hline \multicolumn{9}{|l|}{ Subgroup analyses } \\
\hline \multicolumn{9}{|l|}{ Target group } \\
\hline Older adults & 6 & 0.30 & 0.14 to 0.46 & 22 & 0 to 67 & \multirow[t]{3}{*}{0.11} & 6.0 & \multirow[t]{2}{*}{3.91 to 12.82} \\
\hline Postpartum & 3 & 0.21 & -0.04 to 0.46 & 0 & 0 to 90 & & $\mathrm{NR}^{\mathrm{C}}$ & \\
\hline Other & 5 & 0.52 & 0.32 to 0.71 & 0 & 0 to 79 & & 3.5 & 2.60 to 5.56 \\
\hline \multicolumn{9}{|l|}{ Control group } \\
\hline Care as usual & 8 & 0.28 & 0.10 to 0.46 & 18 & 0 to 61 & \multirow[t]{2}{*}{0.32} & 6.4 & 3.91 to 17.86 \\
\hline Other & 6 & 0.41 & 0.24 to 0.57 & 3 & 0 to 75 & & 4.4 & 3.18 to 7.46 \\
\hline \multicolumn{9}{|l|}{ Psychotherapy } \\
\hline CBT & 8 & 0.42 & 0.28 to 0.55 & 4 & 0 to 69 & \multirow[t]{2}{*}{0.08} & 4.3 & 3.31 to 6.41 \\
\hline Other & 6 & 0.21 & 0.01 to 0.40 & 0 & 0 to 75 & & 8.5 & 4.50 to 166.67 \\
\hline \multicolumn{9}{|l|}{ Treatment format } \\
\hline Individual $^{d}$ & 6 & 0.26 & 0.04 to 0.49 & 44 & 0 to 78 & \multirow[t]{2}{*}{0.37} & 6.9 & 3.68 to 45.45 \\
\hline Group & 8 & 0.39 & 0.24 to 0.53 & 0 & 0 to 68 & & 4.6 & 3.42 to 7.46 \\
\hline \multicolumn{9}{|l|}{ Quality } \\
\hline \multicolumn{9}{|c|}{ Sequence generation } \\
\hline Unclear & 9 & 0.39 & 0.22 to 0.56 & 0 & 0 to 65 & \multirow[t]{2}{*}{0.50} & 4.6 & 3.25 to 8.06 \\
\hline Positive & 5 & 0.30 & 0.12 to 0.49 & 56 & 0 to 84 & & 6.0 & 3.68 to 14.71 \\
\hline \multicolumn{9}{|c|}{ Concealment of allocation } \\
\hline Unclear & 8 & 0.44 & 0.25 to 0.63 & 0 & 0 to 68 & \multirow[t]{2}{*}{0.23} & 4.1 & 2.91 to 7.14 \\
\hline Positive & 6 & 0.29 & 0.14 to 0.44 & 46 & 0 to 79 & & 6.2 & 4.10 to 12.82 \\
\hline \multicolumn{9}{|c|}{ Masking of assessors } \\
\hline Self-report & 11 & 0.40 & 0.28 to 0.52 & 0 & 0 to 60 & \multirow[t]{2}{*}{0.01} & 4.5 & \multirow[t]{2}{*}{3.50 to 6.41} \\
\hline Positive $^{e}$ & 3 & -0.06 & -0.37 to 0.25 & 0 & 0 to 90 & & $\mathrm{NR}^{\mathrm{c}}$ & \\
\hline \multicolumn{9}{|l|}{ Intention to treat } \\
\hline Negative & 4 & 0.38 & 0.06 to 0.71 & 0 & 0 to 85 & \multirow[t]{2}{*}{0.83} & 4.7 & 2.60 to 29.41 \\
\hline Positive & 10 & 0.34 & 0.21 to 0.48 & 27 & 0 to 65 & & 5.3 & 3.76 to 8.47 \\
\hline \multicolumn{9}{|c|}{ Selective outcome reporting } \\
\hline Unclear & 10 & 0.37 & 0.22 to 0.53 & 0 & 0 to 62 & \multirow[t]{2}{*}{0.61} & 4.9 & 3.42 to 8.06 \\
\hline Positive & 4 & 0.30 & 0.08 to 0.52 & 67 & 3 to 89 & & 6.0 & 3.50 to 21.74 \\
\hline Comparison of subcli & & & & & & & & \\
\hline Subclinical & 14 & 0.35 & 0.23 to 0.47 & 13 & 0 to 51 & 0.008 & 5.1 & 3.85 to 7.69 \\
\hline Major depression & 70 & 0.63 & 0.54 to 0.73 & 63 & 52 to 71 & & 2.9 & 2.54 to 3.36 \\
\hline $\begin{array}{l}\text { BDI, Beck Depression Inv } \\
\text { a. According to the rand } \\
\text { b The } P \text { value indicates } \\
\text { c. Numbers needed to tr } \\
\text { d. Includes telephone-ba } \\
\text { e. In one study a clinicia }\end{array}$ & $\begin{array}{l}\text { therapy; } \\
\text { each othe } \\
\text { lot report }\end{array}$ & ES-D, Ce & Epidemiologica & & on scale; & & & \\
\hline
\end{tabular}

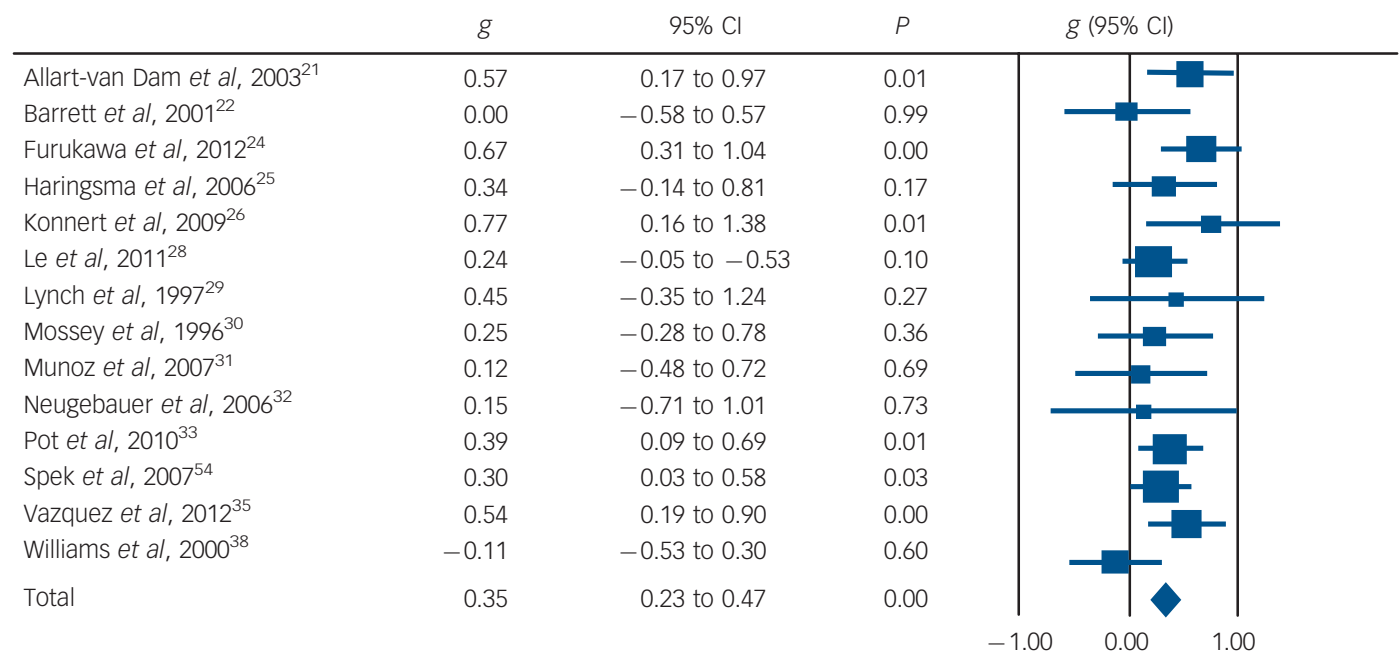

Fig. 2 Standardised effect sizes of psychotherapy for subclinical depression compared with control conditions: Hedges' $g$. 


\begin{tabular}{|c|c|c|c|c|}
\hline & Studies & $\mathrm{RR}^{\mathrm{a}}(95 \% \mathrm{Cl})$ & $I^{2}(95 \% \mathrm{Cl})$ & NNT $(95 \% \mathrm{Cl})$ \\
\hline \multicolumn{5}{|c|}{ Follow-up period } \\
\hline 6 months & 5 & $0.61 *(0.37-0.99)$ & $19(0-83)$ & $10.3^{* *}(6.3-28.6)$ \\
\hline 12 months & 4 & $0.74(0.50-1.10)$ & $0(0-85)$ & $16.4 *(8.5-250)$ \\
\hline 24 months & 2 & $0.61(0.16-2.36)$ & $84^{\mathrm{b}}$ & $\mathrm{NR}^{\mathrm{C}}$ \\
\hline \multicolumn{5}{|c|}{$\begin{array}{l}\text { NNT, number needed to treat; NR, not reported; RR, relative risk. } \\
\text { a. According to the random effects model. } \\
\text { b. Confidence intervals cannot be calculated with two studies. } \\
\text { c. Numbers needed to treat are not reported for non-significant results. } \\
* P<0.05 ;{ }^{* * P} P 0.01 \text {. }\end{array}$} \\
\hline
\end{tabular}

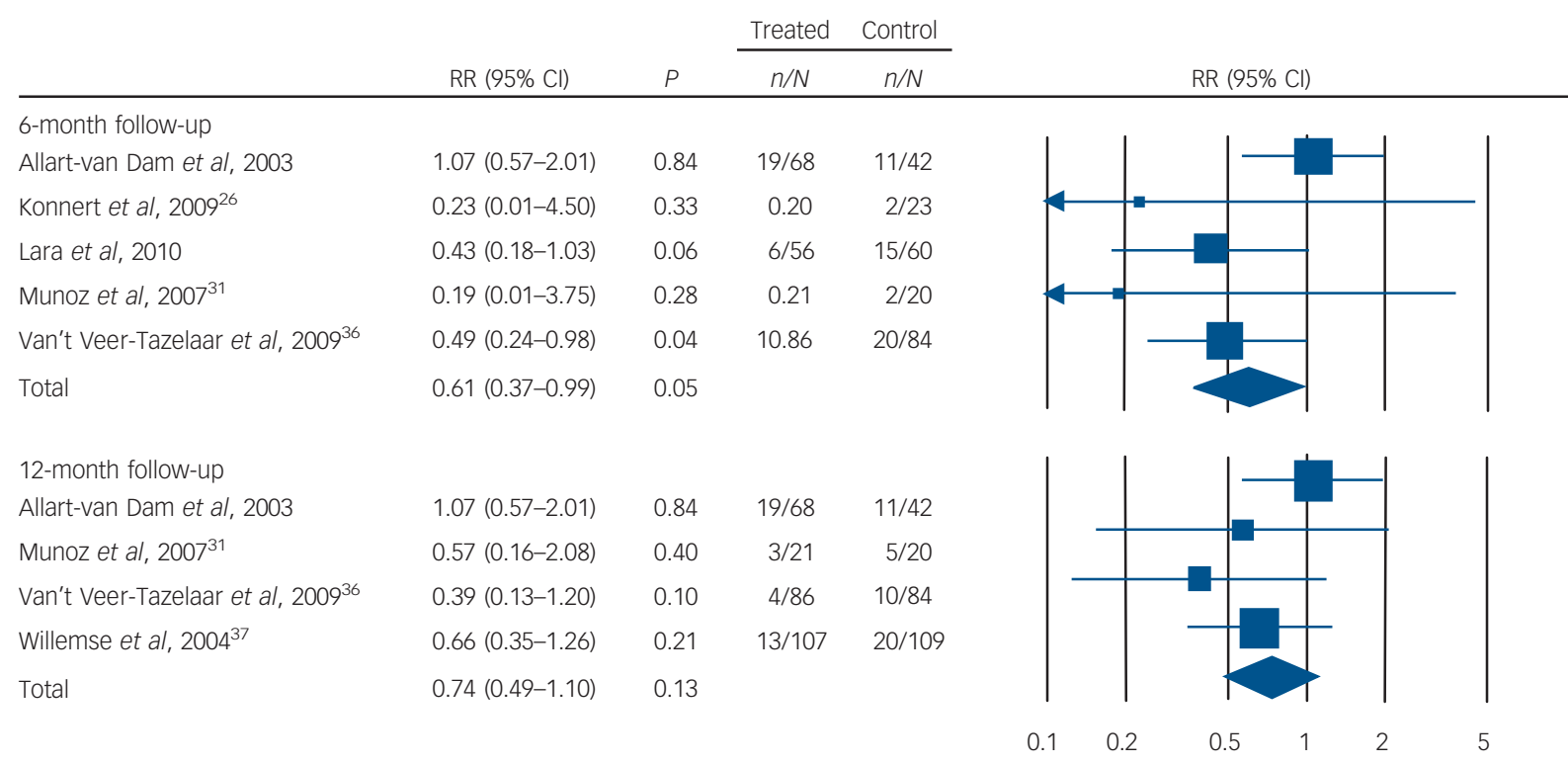

Fig. 3 Effects of psychological treatments on incidence of major depression: risk ratios (RR) at 6-month and 12-month follow-up.

\begin{tabular}{|c|c|c|c|c|}
\hline & \multicolumn{2}{|l|}{ Full model } & \multicolumn{2}{|c|}{ Parsimonious model } \\
\hline & Coefficent $(95 \% \mathrm{Cl})$ & $P$ & Coefficient $(95 \% \mathrm{Cl})$ & $P$ \\
\hline $\begin{array}{l}\text { MDD } v \text {. minor depression } \\
\text { Aimed at adults in general } v \text {. specific group }\end{array}$ & $\begin{array}{l}0.32 \text { (0.10 to } 0.53) \\
0.04(-0.18 \text { to } 0.25)\end{array}$ & $<0.01$ & 0.34 (0.14 to 0.54$)$ & $<0.01$ \\
\hline $\begin{array}{l}\text { Recruitment } \\
\text { Community } \\
\text { Clinical } \\
\text { Other }\end{array}$ & $\begin{array}{c}\text { Reference } \\
-0.07(-0.32 \text { to } 0.19) \\
0.01(-0.26 \text { to } 0.27)\end{array}$ & & & \\
\hline $\begin{array}{l}\text { Individual format (V. group and GSH) } \\
\text { Number of sessions (continuous) } \\
\text { CBT as psychotherapy (dummy) }\end{array}$ & $\begin{array}{r}-0.11(-0.32 \text { to } 0.09) \\
-0.02(-0.04 \text { to } 0.00) \\
0.02(-0.17 \text { to } 0.22)\end{array}$ & & $\begin{array}{l}-0.21(-0.37 \text { to }-0.05) \\
-0.02(-0.04 \text { to }-0.01)\end{array}$ & $\begin{array}{l}<0.05 \\
<0.05\end{array}$ \\
\hline $\begin{array}{l}\text { Control group } \\
\text { Waiting list } \\
\text { Care as usual } \\
\text { Other }\end{array}$ & $\begin{array}{c}\text { Reference } \\
-0.18(-0.42 \text { to } 0.06) \\
-0.15(-0.40 \text { to } 0.10)\end{array}$ & & & \\
\hline $\begin{array}{l}\text { Quality of study (continuous) } \\
\text { Constant }\end{array}$ & $\begin{array}{c}-0.08(-0.14 \text { to }-0.03) \\
0.93(0.59 \text { to } 1.27)\end{array}$ & $\begin{array}{l}<0.01 \\
<0.001\end{array}$ & $\begin{array}{c}-0.09(-0.14 \text { to }-0.04) \\
0.92(0.63 \text { to } 1.22)\end{array}$ & $\begin{array}{l}<0.01 \\
<0.001\end{array}$ \\
\hline
\end{tabular}

that the subset of high-quality studies resulted in a statistically reliable effect, but that does not fully address the clinical heterogeneity of the included studies. Second, the relatively small number of studies should also be reported as a limitation, as this restricts the statistical power to detect differences between subgroups. We did not find any difference between CBT and other psychotherapies, but this may have been caused by inadequate statistical power to detect such differences. On the other hand, there is not much evidence that CBT or any other type of psychotherapy is more effective than other psychotherapies. ${ }^{39} \mathrm{~A}$ third limitation is that the study selection was not done by two independent researchers, although quality assessment and data abstraction were performed independently by two raters. Another concern already mentioned is that most included studies used 
only self-report measures, and that clinician-rated outcomes did not indicate a significant benefit of psychotherapies over control. However, an earlier meta-analysis showed that self-rated instruments are more conservative than clinician-rated instruments when assessing the outcomes of psychotherapy for depression. ${ }^{40}$ The divergence of estimated effects, as a function of self-report $v$. rater-administered scales, could also reflect the differential sensitivity of the BDI and CES-D to psychological effects, whereas scales like the HRSD focus more on neurovegetative symptoms of depression. We also want to stress that the NNTs for the preventive effects of the treatments should be interpreted with caution, because these depend on event rates. Because the event rates in the studies differed considerably from each other (ranging from 0.09 to 0.26 ), the NNTs might be considerably lower when the event rate in the target groups is lower.

\section{Implications}

Psychological therapies may be effective in the treatment of subclinical depression and also may reduce the incidence of major depressive disorder. These results should, however, be confirmed in further randomised trials, because of the clinical heterogeneity, the low quality of the included studies and because the clinicianrated outcomes did not achieve significance.

Pim Cuijpers, PhD, Department of Clinical Psychology, VU University Amsterdam, EMGO Institute for Health and Care Research, VU University and VU University Medical Centre Amsterdam, The Netherlands, and Leuphana University, Lünebrug, Germany; Sander L. Koole, PhD, Department of Clinical Psychology, VU University Amsterdam, EMGO Institute for Health and Care Research, VU University and VU University Medical Centre Amsterdam, The Netherlands; Annemiek van Dijke, PhD, Delta Psychiatrisch Centrum, Poortugaal, The Netherlands; Miquel Roca, MD, PhD Delta Psychiatrisch Centrum, Poortugaal, The Netherlands; Miquel Roca, MD,
Institut Universitari d'Investigació en Ciències de la Salut (IUNICS). Hospital Juan March, Rediapp, University of Balearic Islands, Palma de Mallorca, Spain; Juan Li, PhD, Key Laboratory of Mental Health, Institute of Psychology, Chinese Academy of Sciences, Beijing, China; Charles F. Reynolds III, MD, Department of Psychiatry, University of Pittsburgh School of Medicine, Pittsburgh, USA

Correspondence: Professor Pim Cuijpers, Department of Clinical Psychology and EMGO Institute for Health and Care Research, VU University Amsterdam, Van der Boechorststraat 1, 1081 BT Amsterdam, The Netherlands. Email: p.cuijpers@vu.nl.

First received 13 Sep 2013, final revision 14 Mar 2014, accepted 28 Mar 2014

\section{Funding}

C.F.R. is supported by National Institute of Mental Health grant P30 MH90333; no other financial support was received for this study.

\section{References}

1 Cuijpers P, De Graaf R, Van Dorsselaer S. Minor depression: risk profiles, functional disability, health care use and risk of developing major depression. J Affect Disord 2004; 79: 71-9.

2 Horwarth E, Johnson J, Klerman GL, Weissman MM. Depressive symptoms as relative and attributable risk factors for first-onset major depression. Arch Gen Psychiatry 1992; 49: 817-23.

3 Rucci P, Gherardi S, Tansella M, Piccinelli M, Berardi D, Bisoffi G, et al. Subthreshold psychiatric disorders in primary care: prevalence and associated characteristics. J Affect Disord 2003; 76: 171-81.

4 Chachamovich $\mathrm{E}$, Fleck $\mathrm{M}$, Laidlaw $\mathrm{K}$, Power $\mathrm{M}$. Impact of major depression and subsyndromal symptoms on quality of life and attitudes toward aging in an international sample of older adults. Gerontologist 2008; 48: 593-602.

5 Goldney RD, Fisher LJ, Dal Grande E, Taylor AW. Subsyndromal depression: prevalence, use of health services and quality of life in an Australian population. Soc Psychiatry Psychiatr Epidemiol 2004; 39: 293-8.

6 Cuijpers P, Smit F, Oostenbrink J, de Graaf R, ten Have M, Beekman A Economic costs of minor depression: a population-based study. Acta Psychiatr Scand 2007; 115: 229-36.
7 Cuijpers P, Vogelzangs N, Twisk J, Kleiboer A, Li J, Penninx BW. Differential mortality rates in major and subthreshold depression: meta-analysis of studies that measured both. Br J Psychiatry 2013; 202: 22-7.

8 Barbui C, Cipriani A, Patel V, Ayuso-Mateos JL, van Ommeren M. Efficacy of antidepressants and benzodiazepines in minor depression: systematic review and meta-analysis. Br J Psychiatry 2011; 198: 11-6.

9 Cuijpers P, van Straten A, Smit F. Psychological treatments of subthreshold depression: a meta-analytic review. Acta Psychiatr Scand 2007; 115 434-41.

10 Cuijpers P, van Straten A, Warmerdam L, Andersson G. Psychological treatment of depression: a meta-analytic database of randomized studies. BMC Psychiatry 2008; 8: 36.

11 Higgins JPT, Green S, eds. Cochrane Handbook for Systematic Reviews of Interventions Version 5.1.0. Cochrane Collaboration, 2011.

12 Hedges LV, Olkin I. Statistical Methods for Meta-analysis. Academic Press, 1985.

13 Beck AT, Ward $\mathrm{CH}$, Mendelson M, Mock J, Erbaugh J. An inventory for measuring depression. Arch Gen Psychiatry 1961; 4: 561-71.

14 Hamilton M. A rating scale for depression. J Neurol Neurosurg Psychiatry 1960; 23: 56-62

15 Borenstein M, Hedges LV, Higgins JPT, Rothstein HR. Introduction to Meta-analysis. Wiley, 2009.

16 Kraemer HC, Kupfer DJ. Size of treatment effects and their importance to clinical research and practice. Biol Psychiatry 2006; 59: 990-6.

17 Laupacis A, Sackett DL, Roberts RS. An assessment of clinically useful measures of the consequences of treatment. $N$ Engl J Med 1988; 318 1728-33.

18 Ioannidis JPA, Patsopoulos NA, Evangelou E. Uncertainty in heterogeneity estimates in meta-analyses. BMJ 2007; 335: 914-6.

19 Orsini N, Higgins J, Bottai M, Buchan I. Heterogi: Stata Module to Quantify Heterogeneity in a Meta-analysis. http://EconPapers.repec.org/ RePEc:boc:bocode:s449201.

20 Duval S, Tweedie R. Trim and fill: a simple funnel-plot-based method of testing and adjusting for publication bias in meta-analysis. Biometrics 2000; 56: $455-63$

21 Allart-van Dam E, Hosman CMH, Hoogduin CAL, Schaap CPDR. The Coping with Depression course: short-term outcomes and mediating effects of a randomized controlled trial in the treatment of subclinical depression. Behav Ther 2003; 34: 381-96.

22 Barrett JE, Williams JW, Oxman TE, Frank E, Katon W, Sullivan M, et al. Treatment of dysthymia and minor depression in primary care: a randomized trial in patients aged 18 to 59 years. J Fam Pract 2001; 50: 405-12.

23 Bot M, Pouwer F, Ormel J, Slaets JPJ, de Jonge P. Predictors of incident major depression in diabetic outpatients with subthreshold depression. Diabet Med 2010; 27: 1295-301.

24 Furukawa TA, Horikoshi M, Kawakami N, Kadota M, Sasaki M, Sekiya Y, et al. Telephone cognitive-behavioral therapy for subthreshold depression and presenteeism in workplace: a randomized controlled trial. PLOS One 2012; 7 e35330.

25 Haringsma R, Engels GI, Cuijpers P, Spinhoven P. Effectiveness of the Coping With Depression (CWD) course for older adults provided by the community-based mental health care system in the Netherlands: a randomized controlled field trial. Int Psychogeriatr 2006; 18: 307-25.

26 Konnert C, Dobson K, Stelmach L. The prevention of depression in nursing home residents: a randomized clinical trial of cognitive-behavioral therapy. Aging Ment Health 2009; 13: 288-99.

27 Lara MA, Navarro C, Navarrete L. Outcome results of a psycho-educational intervention in pregnancy to prevent PPD: a randomized control trial. J Affect Dis 2010; 122: 109-17.

28 Le HN, Perry DF, Stuart EA. Randomized controlled trial of a preventive intervention for perinatal depression in high-risk Latinas. J Consult Clin Psychol 2011; 79: 135-41.

29 Lynch DJ, Tamburrino MB, Nagel R. Telephone counseling for patients with minor depression: preliminary findings in a family practice setting. J Fam Pract 1997; 44: 293-8.

30 Mossey JM, Knott KA, Higgins M, Talerico K. Effectiveness of a psychosocial intervention, interpersonal counseling, for subdysthymic depression in medically ill elderly. J Gerontol A Biol Sci Med Sci 1996; 51: M172-8.

31 Munoz RF, Le HN, Ippen CG, Diaz MA, Urizar GG, Soto J, et al. Prevention of postpartum depression in low-income women: development of the mamás $y$ bebés/mothers and babies course. Cogn Behav Pract 2007; 14: 70-83

32 Neugebauer R, Kline J, Markowitz JC, Bleiberg KL, Baxi L, Rosing MA, et al. Pilot randomized controlled trial of interpersonal counseling for subsyndromal depression following miscarriage. J Clin Psychiatry 2006; 67: 1299-304. 
33 Pot AM, Bohlmeijer ET, Onrust S, Melenhorst AS, Veerbeek M, de Vries W. The impact of life review on depression in older adults: a randomized controlled trial. Int Psychogeriatr 2010; 22: 572-81.

34 Spek V, Nyklicek I, Smits N, Cuijpers P, Riper H, Keyzer J, Pop V. Internet-based cognitive behavioural therapy for subthreshold depression in people over 50 years old: a randomized controlled clinical trial. Psychol Med 2007; 37: 1797-806.

35 Vazquez FL, Torres A, Blanco V, Díaz O, Otero P, Hermida E. Comparison of relaxation training with a cognitive-behavioural intervention for indicated prevention of depression in university students: a randomized controlled trial. J Psychiatr Res 2012; 46: 1456-63.

36 Van't Veer-Tazelaar PA, van Marwijk HWJ, van Oppen P, van Hout HPJ, van der Horst $\mathrm{HE}$, Cuijpers $\mathrm{P}$, et al. Stepped-care prevention of anxiety and depression in late life: a randomized controlled trial. Arch Gen Psychiatry 2009; 66: 297-304.
37 Willemse GRWM, Smit F, Cuijpers P, Tiemens BG. Minimal-contact psychotherapy for sub-threshold depression in primary care: randomised trial. Br J Psychiatry 2004; 185: 416-21.

38 Williams JW, Barrett J, Oxman T, Frank E, Katon W, Sullivan M, et al. Treatment of dysthymia and minor depression in primary care: a randomized controlled trial in older adults. JAMA 2000; 284: 1519-26.

39 Cuijpers P, van Straten A, Andersson G, van Oppen P. Psychotherapy for depression in adults: a meta-analysis of comparative outcome studies. J Consult Clin Psychol 2008; 76: 909-22.

40 Cuijpers P, Li J, Hofmann SG, Andersson G. Self-reported versus clinicianrated symptoms of depression as outcome measures in psychotherapy research on depression: a meta-analysis. Clin Psychol Rev 2010; 30: 768-78.

\section{poem}

\section{The Man He Killed}

\section{Thomas Hardy}

'Had he and I but met

By some old ancient inn

We should have sat us down to wet

Right many a nipperkin!

'But ranged as infantry,

And staring face to face,

shot at him as he at me

And killed him in his place.

'I shot him dead because -

Because he was my foe

Just so: my foe of course he was;

That's clear enough; although

'He thought he'd 'list, perhaps,

Off-hand like - just as I -

Was out of work - has sold his traps -

No other reason why.

'Yes; quaint and curious war is!

You shoot a fellow down

You'd treat if met where any bar is,

or help to half-a-crown.

Selected by Femi Oyebode. 